\title{
\begin{tabular}{l|l} 
Mibraries & DSpace@MIT
\end{tabular}
}

\author{
MIT Open Access Articles
}

\section{Biaryl Phosphine Based Pd(II) Amido Complexes: The Effect of Ligand Structure on Reductive Elimination}

The MIT Faculty has made this article openly available. Please share how this access benefits you. Your story matters.

Citation: Arrechea, Pedro Luis, and Buchwald, Stephen L. “Biaryl Phosphine Based Pd(II) Amido Complexes: The Effect of Ligand Structure on Reductive Elimination." Journal of the American Chemical Society 138, 38 (September 2016): 12486-12493 (c) 2016 American Chemical Society

As Published: http://dx.doi.org/10.1021/JACS.6B05990

Publisher: American Chemical Society (ACS)

Persistent URL: http://hdl.handle.net/1721.1/113057

Version: Final published version: final published article, as it appeared in a journal, conference proceedings, or other formally published context

Terms of Use: Article is made available in accordance with the publisher's policy and may be subject to US copyright law. Please refer to the publisher's site for terms of use. 


\title{
Biaryl Phosphine Based Pd(II) Amido Complexes: The Effect of Ligand Structure on Reductive Elimination
}

\author{
Pedro Luis Arrechea* and Stephen L. Buchwald* \\ Department of Chemistry, Massachusetts Institute of Technology, 77 Massachusetts Avenue, Cambridge Massachusetts 02319, \\ United States
}

\section{Supporting Information}

ABSTRACT: Kinetic studies conducted under both catalytic and stoichiometric conditions were employed to investigate the reductive elimination of RuPhos (2-dicyclohexylphosphino- 2 ', 6'-diisopropoxybiphenyl) based palladium amido complexes. These complexes were found to be the resting state in Pd-catalyzed cross-coupling reactions for a range of aryl halides and diarylamines. Hammett plots demonstrated that $\mathrm{Pd}(\mathrm{II})$ amido complexes derived from electron-deficient aryl halides or electron-rich diarylamines undergo faster rates of reductive elimination. A Hammett study employing SPhos (2-dicyclohexylphosphino-2',6'-dimethoxybiphenyl) and analogues of SPhos demonstrated that electron donation of the "lower" aryl group is key to the stability of the amido complex with respect to reductive elimination. The rate of reductive elimination of an amido complex based on a BrettPhos-RuPhos hybrid ligand (2(dicyclohexylphosphino)-3,6-dimethoxy-2',6'-diisopropoxybiphenyl) demonstrated that the presence of the 3-methoxy substituent on the "upper" ring of the ligand slows the rate of reductive elimination. These studies indicate that reductive elimination occurs readily for more nucleophilic amines such as $N$-alkyl anilines, $N, N$-dialkyl amines, and primary aliphatic amines using this class of ligands.

\section{INTRODUCTION}

The palladium-catalyzed cross-coupling of amines and aryl halides is a widely employed process for the synthesis of anilines in both academic and industrial settings. This process has been applied to a wide range of substrate combinations and has been utilized for both discovery efforts and at the multikilogram scale. ${ }^{1,2}$ The broad synthetic utility of this process has been aided by mechanistic studies. Several generations of ligands, beginning with $\mathrm{P}(o \text {-tolyl })_{3}{ }^{3}$ followed by bidentate ligands (e.g., DPPF, BINAP), ${ }^{4,5}$ and subsequently by $\mathrm{P}\left({ }^{\mathrm{t}} \text { butyl }\right)_{3}{ }^{6}$ and dialkybiarylphosphines, ${ }^{7}$ and more complex ferrocene based ligands, ${ }^{8}$ have all been successfully employed in these reactions. The newer catalyst systems have allowed for a broader substrate scope and the use of milder bases, manifest greater functional group compatibility, and can be carried out at lower reaction temperatures. ${ }^{9}$ An increased understanding of the newer versions of this transformation as well the structure of the palladium intermediates involved is critical to the development of future generations of ligands.

The cross-coupling reaction of amines and aryl halides is believed to proceed through four key intermediates (I-IV) (Scheme 1A): a phosphine-ligated palladium(0) complex and three palladium(II) complexes. In one now commonly employed version, an amine-ligated oxidative addition complex P1 (precatalyst) is activated by a strong base, after which this complex undergoes reductive elimination to produce indoline and generate a phosphine-ligated palladium $(0)$ intermediate (I). Intermediate I then undergoes oxidative addition with an aryl halide to produce a palladium(II) intermediate (II), which
Scheme 1. (A) Proposed Mechanism for C-N CrossCoupling with the Reductive Elimination Step Highlighted in Red; (B) Palladium-Catalyzed Cross-Coupling of 3Bromoanisole with Diphenylamine; (C) Constant Rate Observed by Reaction Calorimetry with Two Different L1 Concentrations

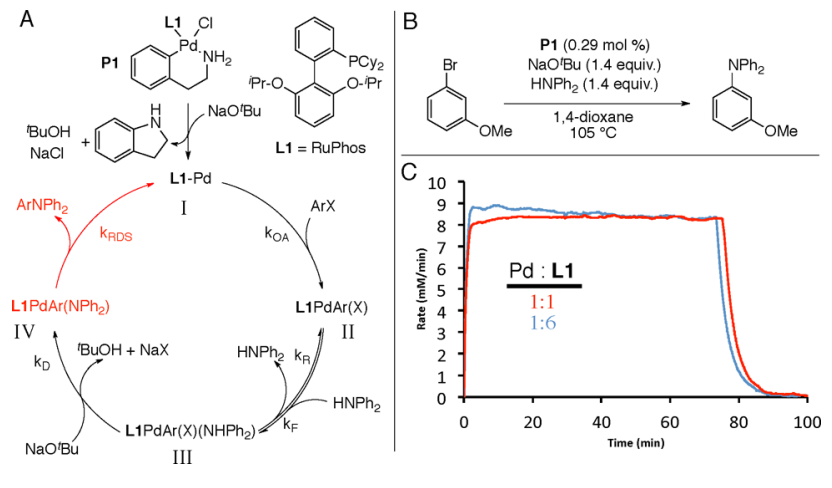

can form an amine-bound palladium complex (III) that subsequently reacts with base to form an amido complex (IV). Intermediate IV then undergoes reductive elimination to afford the amine product and regenerate $\mathbf{I}$, thus completing the catalytic cycle. Undoubtedly, this is an oversimplified depiction of the actual mechanism since it ignores the potential

Received: June 10, 2016

Published: August 25, 2016 
consequences of different palladium(II) stereoisomers, ${ }^{10}$ offcycle species, ${ }^{11}$ or palladium aggregates.

Measurement of the rate of individual elementary steps such as oxidative addition or reductive elimination under both catalytic and stoichiometric conditions using complexes derived from the widely employed dialkylbiarylphosphine ligands would provide significant insight into the details of the reaction mechanism. Furthermore, discrepancies between catalytic and stoichiometric studies, if they occur, can presumably be attributed to other steps in the catalytic cycle or to off-cycle processes. An identification of these processes would provide useful insight leading to the development of better ligands and catalyst systems.

Reductive elimination is the bond-forming elementary step in cross-coupling reactions. In the Pd-catalyzed $\mathrm{C}-\mathrm{N}$ coupling reaction, this step occurs from intermediate IV. Thus, an understanding of the structure and reactivity of these amido complexes is of importance. Shortly after the first publications on tin-free palladium-catalyzed $\mathrm{C}-\mathrm{N}$ cross-coupling, ${ }^{3 \mathrm{a}, 12}$ Boncella reported the synthesis of square-planar trans$\left(\mathrm{PMe}_{3}\right)_{2} \mathrm{Pd}(\mathrm{Ph})(\mathrm{NHPh})$. Thermolysis at $90{ }^{\circ} \mathrm{C}$ resulted in the loss of $\mathrm{a} \mathrm{PMe}_{3}$ and the formation of a dimeric complex where the anilide serves as a bridging ligand. Upon prolonged heating at $110{ }^{\circ} \mathrm{C}$, this complex underwent cis-trans isomerization followed by the reductive elimination of diphenylamine. Subsequently, Hartwig characterized amido complexes based on the bidentate ligand, DPPF, which enforces a cis-square-planar geometry. ${ }^{13}$ An amido complex derived from $\mathrm{HN}(\text { tolyl })_{2}$ underwent reductive elimination at 85 ${ }^{\circ} \mathrm{C}$ while the analogous anilide complex underwent reductive elimination at $25{ }^{\circ} \mathrm{C}$ in a similar time frame. An alkylamide complex based on iso-butyl amine underwent reductive elimination at $0{ }^{\circ} \mathrm{C}$. In conjunction with other studies, the authors concluded that intermediates derived from electrondeficient aryl halides and electron-rich amines enhanced the rate of reductive elimination. They also prepared and structurally characterized a $\mathrm{T}$-shaped complex based on $\mathrm{P}\left({ }^{t} \mathrm{Bu}\right)_{3}$ in which the aryl ligand was located trans to the open coordination site. Despite possessing an extremely electrondeficient diarylamido group, the complex readily underwent reductive elimination, thus providing a compelling demonstration that three coordinate complexes are particularly prone to reductive elimination. ${ }^{13 e, 14}$

Toward the goal of characterizing relevant palladium intermediates with dialkylbiarylphosphines as supporting ligands, we had previously prepared and characterized oxidative addition complexes ${ }^{15}$ and an amine-bound palladium(II) complex. ${ }^{16}$ We have also synthesized and characterized palladium(0) complexes that approximate the presumed catalytic intermediate $\mathbf{I}^{17}$ Despite much effort, we had been unable to isolate palladium amido complexes supported with biaryl phosphine ligands because of their proclivity to reductively eliminate. During an investigation of the kinetics of the cross-coupling of secondary amines using a RuPhos (L1) based catalyst, ${ }^{18}$ we noted that the reaction using a combination of diphenylamine and 3-bromoanisole gave kinetics consistent with the amido complex (IV) as the resting state which was confirmed by further work. We then examined the role of the supporting biaryl ligand and coupling partners on the rate of reductive elimination. Herein, we report our findings that include the synthesis and systematic study of a series of palladium(II) amido complexes supported by dialkylbiarylphosphine ligands.

\section{RESULTS}

A. Kinetic Studies of a RuPhos (L1) Based PalladiumCatalyzed Cross-Coupling of 3-Bromoanisole and Diphenylamine: Isolation and Characterization of the Amido Complex. We began by examining the rate of reaction for the cross-coupling of diphenylamine and 3-bromoanisole using P1 (0.29 mol \%) at $105{ }^{\circ} \mathrm{C}$ (Scheme 1B). Employing reaction calorimetry, we found that the rate was independent of the concentration of amine, base, and aryl halide (Scheme 1C). Furthermore, the rate was directly proportional to P1. For example, doubling the catalyst concentration doubled the rate and halved the reaction time. The inclusion of additional $\mathbf{L} \mathbf{1}$ did not significantly affect the reaction rate. ${ }^{8 b, 19}$ In order to gain further insight, we examined the reaction by ${ }^{31} \mathrm{P} \mathrm{NMR}$ at $80{ }^{\circ} \mathrm{C}$ in dioxane- $d_{8}$ using $2 \mathrm{~mol} \% \mathbf{P 1}$. We observed only one resonance at $33 \mathrm{ppm}$. This is consistent with a single palladiumcontaining species as the resting state.

On the basis of these observations, we surmised that the ratedetermining step $\left(k_{\mathrm{RDS}}\right)$ was likely reductive elimination from the amido complex (Scheme 1A). By variation of the catalyst loading and the reaction temperature, we indirectly measured the rate constant for reductive elimination. By making the assumption that all of the palladium was in the form of the amido complex (IV), we calculated the rate constant for reductive elimination $\left(k_{\mathrm{RE}}\right)$ using eq 1 which relates the amount of palladium relative to the limiting reagent and the time for the reaction to go to completion $\left(\tau_{\mathrm{RXN}}\right):{ }^{20}$

$$
k_{\mathrm{RE}}=k_{\mathrm{RDS}}=\frac{1}{\left(\mathrm{Pd}_{\text {ratio }}\right) \tau_{\mathrm{RXN}}}
$$

For example, a reaction taking $100 \mathrm{~min}$ to go to completion with $1 \mathrm{~mol} \%$ loading of catalyst $\left(\mathrm{Pd}_{\text {ratio }}=0.01\right)$ will have a calculated rate constant for reductive elimination of 1.0 $\left(\mathrm{min}^{-1}\right)$. Using this relationship, ${ }^{21}$ we performed rate measurements with several different catalyst loadings, ranging from 0.058 to $1.3 \mathrm{~mol} \%$, and at temperatures from 78 to $110{ }^{\circ} \mathrm{C}$ to construct an Eyring plot (Chart 1; see Supporting Information (SI) Figures S7-S10). The calculated enthalpy of activation $\left(\Delta H^{\ddagger}, 25 \mathrm{kcal} / \mathrm{mol}\right)$ and entropy of activation $\left(\Delta S^{\ddagger}, 2.9 \mathrm{cal} /\right.$ $(\mathrm{mol} \mathrm{K}))$ are comparable to reductive elimination processes seen for platinum complexes. ${ }^{22}$ These kinetic parameters allow

Chart 1. Eyring Plot Based upon Kinetics of the Pd-

Catalyzed Coupling of Diphenylamine and 3-Bromoanisole ${ }^{a}$

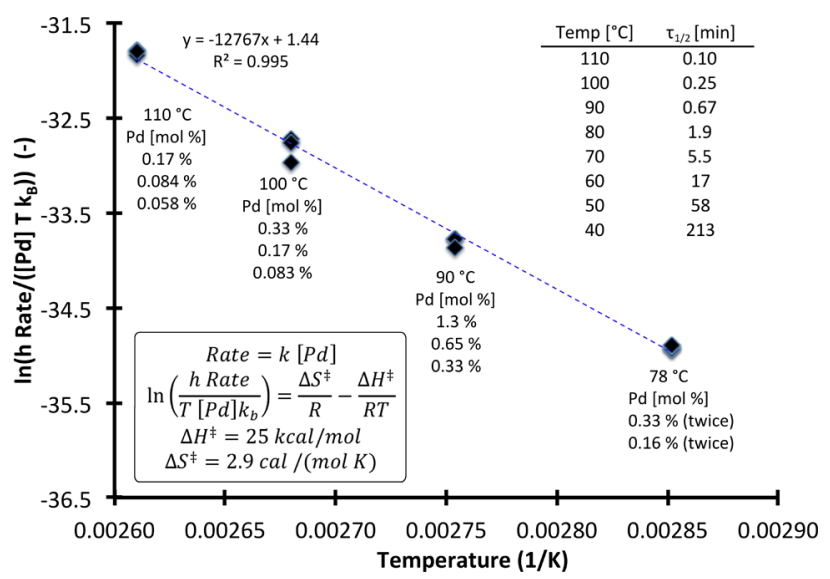

${ }^{a}$ The table inset contains calculated half-lives of the amido complex (IV) based on the regression analysis. 
us to indirectly calculate the half-life, $\tau_{1 / 2}$, of the presumed amido complex as a function of temperature. On the basis of this calculation, we predicted that the complex should have a half-life of $213 \mathrm{~min}$ at $40{ }^{\circ} \mathrm{C}$. At $25{ }^{\circ} \mathrm{C}$, the half-life of the complex was calculated to be $30 \mathrm{~h}$ (Chart 1 , table inset).

If this prediction is correct, the amido complex (IV) should be stable at room temperature and should be isolable. We thus prepared it by first synthesizing the corresponding oxidative addition complex OAla (Scheme 2). The preparation of amido

Scheme 2. Synthesis of Amido Complex (IV/A1a)

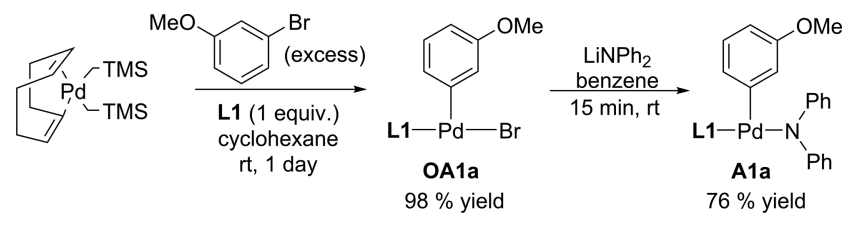

complex Ala (Scheme 2) was achieved by the addition of OA1a to a solution of lithium diphenylamide, followed by filtration to remove the insoluble lithium bromide that had formed. The product was then crystallized from pentane to grow single crystals suitable for X-ray diffraction (Figure 1). At

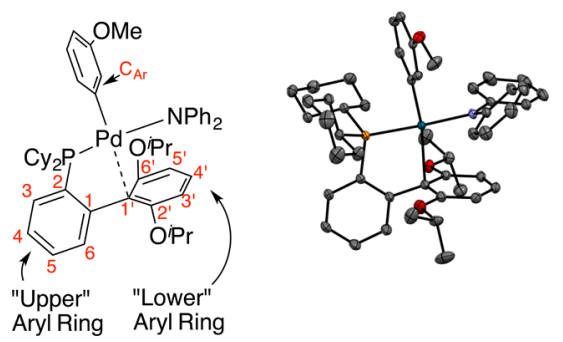

Figure 1. ORTEP drawing of (L1) $\mathrm{Pd}\left(\mathrm{NPh}_{2}\right)\left(3-\mathrm{C}_{6} \mathrm{H}_{4} \mathrm{OMe}\right)$, Ala. Hydrogen atoms are omitted for clarity.

$20{ }^{\circ} \mathrm{C}$, the ${ }^{31} \mathrm{P}$ NMR resonance of the isolated complex had a signal $(33 \mathrm{ppm})$ identical to that seen in the monitoring of the catalytic reaction at $80{ }^{\circ} \mathrm{C}$. Furthermore, the complex had the same red color observed during the catalytic reaction.

As shown in Figure 1, the interaction of the palladium atom with $\mathrm{C}^{\prime}$ is sufficient to affect the geometry of the lower aryl ring. The distortion at this carbon atom is indicative of its partial $\mathrm{sp}^{3}$-character. The deflection of $\mathrm{C} 1, \mathrm{Cl}^{\prime}$, and $\mathrm{C}^{\prime}$ from linearity is $22^{\circ}$. The bond lengths between the $\mathrm{C1}^{\prime}$ and the $\mathrm{C}^{\prime} / \mathrm{C}^{\prime}$ atoms are longer than the typical length of aryl carbon-carbon bonds (1.42 $\AA$ vs $1.39 \AA$ ) but shorter than an $\mathrm{sp}^{3}-\mathrm{sp}^{3}$ bond $(1.54 \AA)$. The geometry at the palladium is square planar though the bond angles are distorted. The $\mathrm{C}_{\mathrm{Ar}}-$ $\mathrm{Pd}-\mathrm{P}$ bond angle $\left(89.86^{\circ}\right)$ and the $\mathrm{N}-\mathrm{Pd}-\mathrm{C}_{\mathrm{Ar}}\left(87.56^{\circ}\right)$ are close to the ideal $90^{\circ}$ angle. The $\mathrm{P}-\mathrm{Pd}-\mathrm{Cl}^{\prime}\left(81.79^{\circ}\right)$ and $\mathrm{N}-$ $\mathrm{Pd}-\mathrm{C1}^{\prime}\left(100.81^{\circ}\right)$ bond angles deviate significantly from this ideal.

Due to the poor solubility of the amido complex Ala in dioxane- $d_{8}$, we examined the reductive elimination reaction by ${ }^{31} \mathrm{P}$ NMR at 40 and $50{ }^{\circ} \mathrm{C}$ in benzene- $d_{6}$. The complex underwent reductive elimination as a first order process with a measured half-life of $140 \mathrm{~min}$ at $40^{\circ} \mathrm{C}$ and $42 \mathrm{~min}$ at $50{ }^{\circ} \mathrm{C}$. This compares well with the respective predicted values of 213 and $58 \mathrm{~min}$ determined from kinetic studies of the catalytic process (Chart 1 , table inset). This is particularly so given that the sets of experiments were necessarily carried out under changed reaction conditions and in different solvents. ${ }^{23}$

B. Hammett Plots Using an L1 Based Palladium Catalyst. Having established that reductive elimination is the rate-determining step for the reaction of diphenylamine and 3bromoanisole, we investigated the role of the aryl halide and diarylamine under both stoichiometric and catalytic reaction conditions. These studies were carried out by measuring the kinetics under catalytic conditions while changing the aryl halide (electrophile). The kinetics of the reductive elimination of the corresponding amido complexes was then examined. The results from the catalytic and stoichiometric experiments were then compared. A second set of studies was carried out in parallel where the electronic nature of the diarylamine (nucleophile) was varied and the effects on both the catalytic and stoichiometric processes were compared.

We found that the use of either palladacycle P1 or the oxidative addition complex OAla gave identical results for the coupling of 3-bromoanisole with diphenylamine and chose to use OAla as our palladium source for all subsequent studies. We performed each catalytic reaction multiple times with separately prepared batches of OAla. To facilitate the calorimetric studies, the catalyst loading for each substrate combination was adjusted to afford an experimentally convenient reaction time. All reactions under catalytic conditions afforded yields exceeding $90 \%$, as determined by gas chromatography analysis using the isolated product standardized against $n$-dodecane.

As expected, these reactions gave rate laws consistent with reductive elimination as the rate-determining step (see SI, Figures S11-S21). Interestingly, in a comparison with the reaction of bromobenzene with the reaction of chlorobenzene (Chart 2A), the reaction of chlorobenzene exhibited an average rate that was approximately $20 \%$ lower. Likewise, the comparison of the rate of reaction of 3-bromoanisole with the rate of reaction of 3-chloroanisole shows that the aryl chloride is about $10 \%$ lower (Chart $2 \mathrm{~A}$ ). This suggests that the other reaction steps involving the chloride (i.e., oxidative addition/transmetalation) may affect the overall reaction rate. Additionally, in some instances employing electron-rich aryl halides, the rate of reaction was observed to decrease over time (see SI, Figures S16-S19). ${ }^{24}$ Though reductive elimination is still the dominant rate-determining step, the catalytic reaction rate does not exclusively depend on the rate constant for reductive elimination.

We then wanted to compare the kinetics of the Pd-catalyzed process with the rate of reductive elimination determined from the stoichiometric complexes (see SI, Figures S14 and S20). These amido complexes were prepared as for Ala (Scheme 2) and are listed in Table 1B. A measurement of the rate of reductive elimination for these complexes $(\mathbf{A l a}-\mathbf{A 1 i})$ at $80{ }^{\circ} \mathrm{C}$ using ${ }^{31} \mathrm{P}$ NMR was not convenient as the rates of the reactions were too rapid. Thus, they were measured at $40{ }^{\circ} \mathrm{C}$ in benzene$d_{6}$ (Chart 2, table). For most examples, the relative rates of reductive elimination for both stoichiometric and catalytic studies were comparable across the two different temperatures and conditions (Chart 2). Even at this temperature, the halflives for the consumption of Alb (Table 1B), which is derived from an electron-poor aryl halide, and Alf (Table 1B), which is derived from an electron-rich diarylamine, were on the order of minutes making an accurate measurement difficult, and thus, the corresponding relative kinetic values compare poorly with those obtained from measurements of the catalytic reaction. 
Chart 2. (A) Hammett Plot of Pd Based Reactions of Aryl Halides with Diphenylamine and (B) Hammett Plot of the Pd Based Reactions of Diarylamines with Bromobenzene ${ }^{g}$
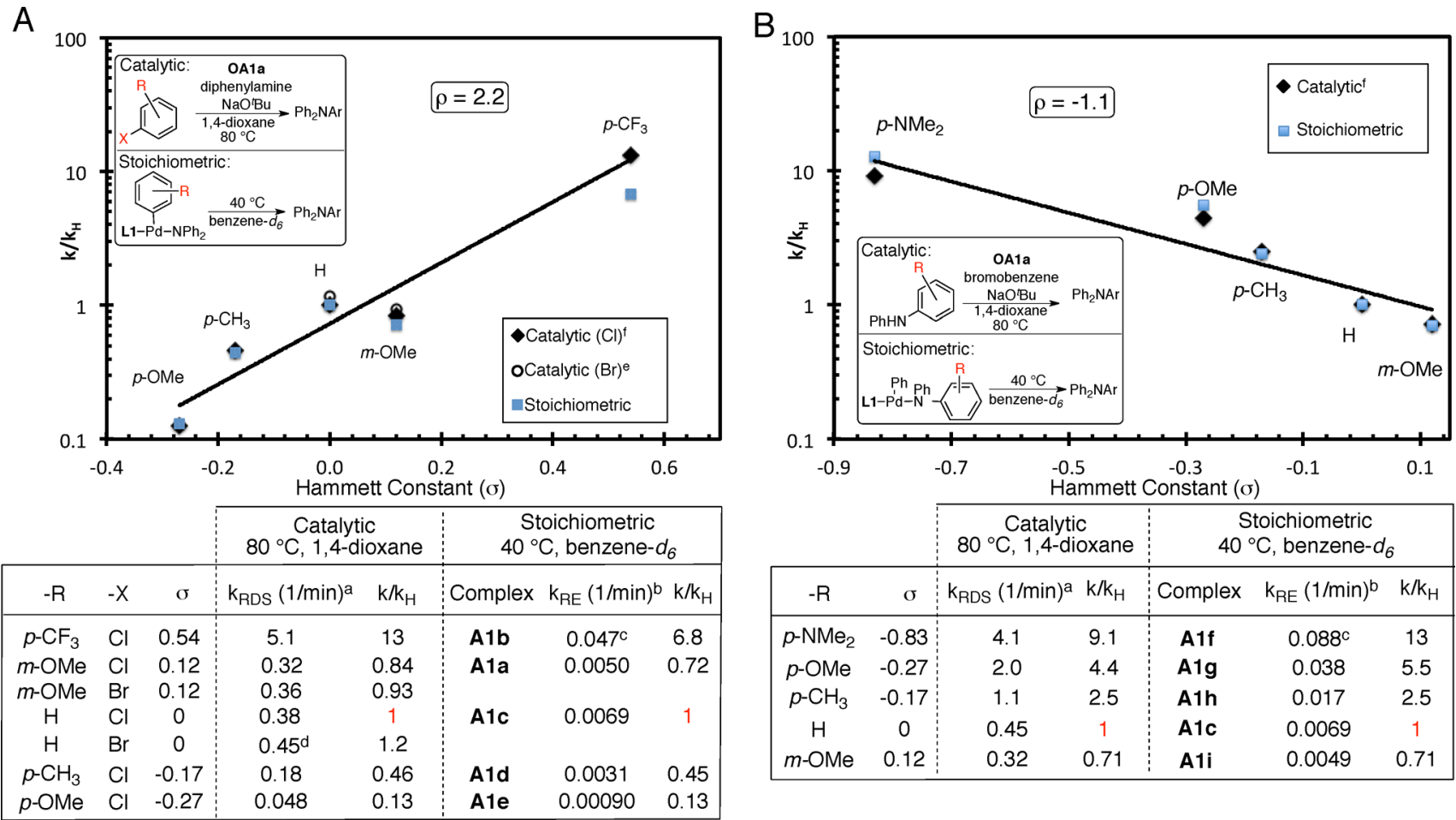

${ }^{a}$ As determined from kinetics of the catalytic reaction at $80{ }^{\circ} \mathrm{C}$. ${ }^{b}$ Determined from the corresponding stoichiometric complex at $40{ }^{\circ} \mathrm{C}$. ${ }^{c}$ Corresponding complex could not be cleanly isolated. ${ }^{d}$ Value taken from entry with $\mathrm{R}=\mathrm{H}$ (catalytic) in part B. ${ }^{e}$ The regression for part A excluded those values corresponding to aryl bromides. ${ }^{f_{\mathrm{T}}}$ The regression is done using only the catalytic reaction results. ${ }^{g} \mathrm{~A}$ larger reproduction of these figures is given in the SI (Figures S15 and S21). Rate constants derived from experiments of the catalytic reaction are averaged values from several runs.

Table 1. (A) Synthesis of Oxidative Addition Complexes and (B) Synthesis of Corresponding Amido Complexes

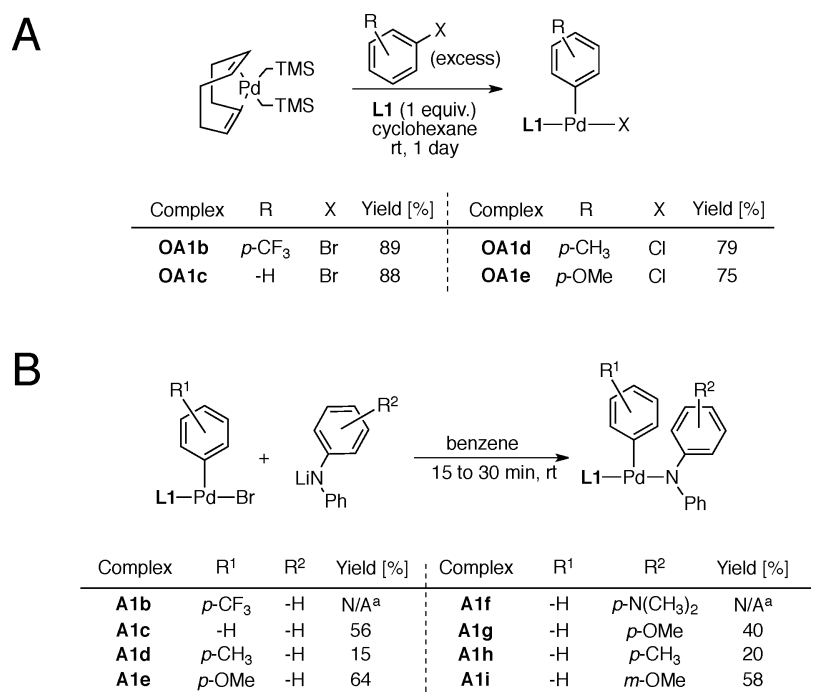

${ }^{a}$ Product could not be cleanly isolated at room temperature due to its instability toward reductive elimination.

The $\rho$ value determined from the kinetics of the catalytic reaction for different aryl halides was 2.2 while that from the corresponding study for different diarylamines was -1.1 . Thus, these studies demonstrate that intermediates with electrondeficient aryl groups and/or electron-rich diarylamido groups undergo reductive elimination at increased rates. This is consistent with what has been shown in previous studies of reductive elimination for the palladium-catalyzed coupling of amines and aryl halides. ${ }^{25}$ The correlation between the rates of catalytic and stoichiometric experiments strongly supports the notion that the amido complex (IV) is the resting state and that reductive elimination is the dominant rate-determining step for the catalytic reaction.

\section{Role of Ligand Structure on the Rate of Reductive} Elimination for the Palladium-Catalyzed $\mathrm{C}-\mathrm{N}$ Coupling Reaction under Catalytic Conditions. As we have demonstrated, one can infer the rate constant for reductive elimination from kinetic studies conducted under catalytic conditions when reductive elimination is the rate-determining step. The rate constant for reductive elimination imposes a maximum rate (or a minimum reaction time) for a reaction. Therefore, for examples where the rate law is not consistent with reductive elimination as the rate-determining step, eq 1 can be modified to calculate a lower limit for the rate constant as shown in eq 2.

$$
k_{\mathrm{RE}}>\frac{1}{\left(\mathrm{Pd}_{\text {ratio }}\right) \tau_{\mathrm{RXN}}}
$$

Given our success (above) in comparing the rate of the reaction under catalytic conditions with the rate of reductive elimination of the amido complex using $\mathbf{L} \mathbf{1}$, we examined the palladiumcatalyzed coupling of 3-bromoanisole and diphenylamine as a model reaction to estimate the stability of the amido complex intermediate (IV) as a function of ligand structure (Table 2A). These model reactions were performed at $105{ }^{\circ} \mathrm{C}$ with a range of catalyst loadings (Table 3). Yields were greater than $90 \%$ as 
Table 2. (A) Ligands and Precatalysts and (B) Oxidative Addition Complexes with Different Supporting Ligands

A
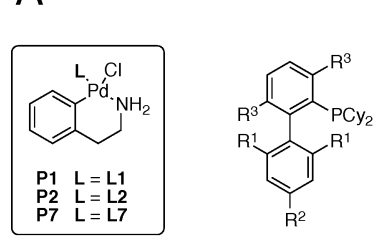

\begin{tabular}{ccccc} 
Ligand & Name & $\mathrm{R}^{1}$ & $\mathrm{R}^{2}$ & $\mathrm{R}^{3}$ \\
\hline L1 & RuPhos & $-\mathrm{O} P r$ & $-\mathrm{H}$ & $-\mathrm{H}$ \\
L2 & SPhos & $-\mathrm{OMe}$ & $-\mathrm{H}$ & $-\mathrm{H}$ \\
L3 & Hybrid & $-\mathrm{O} P r$ & $-\mathrm{H}$ & $-\mathrm{OMe}$ \\
L4 & MethoxySPhos & $-\mathrm{OMe}$ & $-\mathrm{OMe}$ & $-\mathrm{H}$ \\
L5 & AminoSPhos & $-\mathrm{OMe}$ & $-\mathrm{N}\left(\mathrm{CH}_{3}\right)_{2}$ & $-\mathrm{H}$ \\
L6 & BrettPhos & $-\mathrm{Pr}$ & $-\mathrm{Pr}$ & $-\mathrm{OMe}$ \\
L7 & XPhos & $-\mathrm{Pr}$ & $-\mathrm{Pr}$ & $-\mathrm{H}$ \\
L8 & CyJohnPhos & $-\mathrm{H}$ & $-\mathrm{H}$ & $-\mathrm{H}$ \\
L9 & CPhos & $-\mathrm{N}\left(\mathrm{CH}_{3}\right)_{2}$ & $-\mathrm{H}$ & $-\mathrm{H}$
\end{tabular}

B

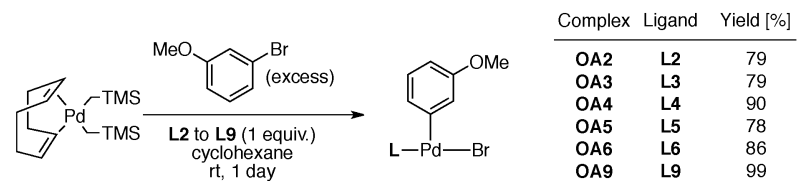

determined by gas chromatography with $n$-dodecane as internal standard.

Table 3. Supporting Ligands Evaluated under Catalytic Conditions

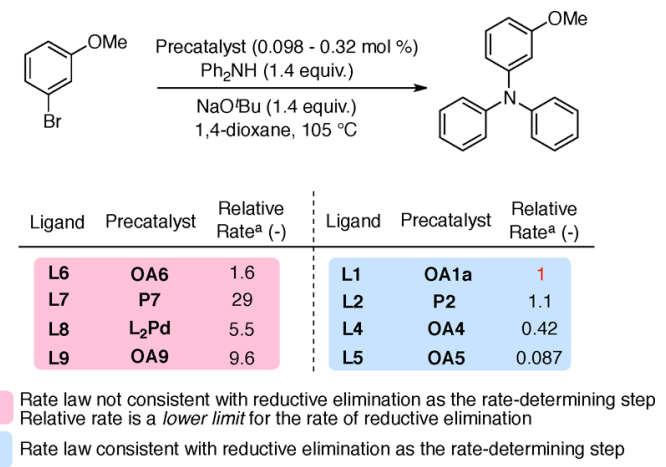

${ }^{a}$ Relative rate refers to the time of the reaction to go to completion compared to the control reaction based on OA1a. A ratio of 0.5 means that the reaction takes twice as long compared to a reaction based on OAla at the same catalyst loading.

Several different precatalysts were used because the corresponding 3-bromoanisole oxidative addition (OA) complexes could not be readily isolated for every ligand studied. In the case of SPhos (L2) and XPhos (L7), a first generation precatalyst $^{16 \mathrm{~b}}$ (P2 and P7) was used. We found that the use of the SPhos-derived OA complex OA2 gave identical results as when $\mathbf{P} 2$ was employed. For $\mathbf{L 8}$, the $\mathrm{L}_{2} \mathrm{Pd}$ complex as described by Fink $^{26}$ was prepared. In this case, the OA complex was generated in situ by addition of 3-iodoanisole and then immediately used without isolation (see SI, Figure S25 and Table S79). ${ }^{27}$

Despite differences in steric demand between L7 and L8, catalysts based on these ligands both completed the reaction at rates much faster than catalysts based on L1 or L2. Since L7 and $\mathbf{L} 8$ both possess electron-deficient "lower" aryl rings (see Figure 1 for numbering) when compared to $\mathbf{L} \mathbf{1}$ and $\mathbf{L} 2$, the electronic properties of the "lower" aryl group appeared to strongly influence the rate of reductive elimination.

We hypothesized that an electron-rich "lower" aryl ring would lower the rate of reductive elimination since it would coordinate more strongly to the $\mathrm{Pd}(\mathrm{II})$ center in the intermediate amido complex. ${ }^{14}$ To test this hypothesis, we prepared two variations of $\mathbf{L} 2$, one of which had a methoxy group (L4) and the other a dimethyl amino group (L5) (Table 2A) at the para position of the "lower" aryl ring of the biaryl group. Consistent with this notion, the coupling reaction employing a catalyst based on L4 proceeded with a rate that was less than half that for a catalyst based on $\mathbf{L 1}$ or $\mathbf{L}$. Likewise, the same reaction employing a catalyst based on L5 which possesses an even more electron-rich "lower" ring proceeded at a rate that was one-tenth of that seen with either L1 or L $\mathbf{2}$ based catalyst. Both of these catalysts completed the reaction with rate laws consistent with reductive elimination as the rate-determining step.

For a catalyst based upon CPhos (L9), the rate law was not consistent with reductive elimination as the rate-determining step. Furthermore, the same coupling reaction was completed in shorter time than with an $\mathbf{L} \mathbf{1}$ based catalyst. This demonstrates that an L9 based amido complex undergoes reductive elimination more readily than an amido complex based upon L1. It has been previously argued that the dimethyl amino groups are unable to attain a planar conformation due to the steric interference of the "upper" aryl ring. This may result in the nitrogen lone pairs being unable to donate their electron density into the $\pi$-system of the "lower" aryl ring. ${ }^{19 c, 28 c}$

D. Role of Ligand Structure on the Rate of Reductive Elimination from Palladium Based Diphenylamido Complexes. The results of the catalytic coupling reactions prompted us to prepare amido complexes from OA complexes based on L2, L3, L4, and L5 (Table 4). As expected, amido

Table 4. Synthesis of Corresponding Amido Complexes

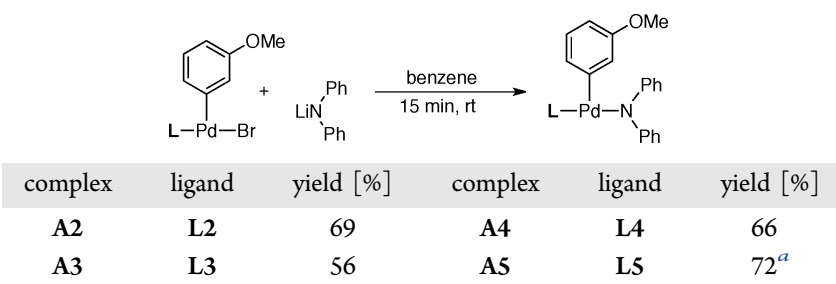

${ }^{a}$ Reaction time was $60 \mathrm{~min}$.

complexes based on SPhos (L2/A2) and RuPhos (L1/A1a) gave similar rates of reductive elimination as determined by ${ }^{31} \mathrm{P}$ $\mathrm{NMR}$ at $50{ }^{\circ} \mathrm{C}$ in benzene- $d_{6}$. Complexes based on ligands with more electron-rich "lower" aryl rings A4 and A5 underwent reductive elimination more slowly, results that compared well with the relative rates estimated from the catalytic processes that were determined by calorimetry (Table 3 and Chart 3 ).

Because of the importance ${ }^{15 a, 28}$ of BrettPhos (L6) (and its structural analogues) in many cross-coupling transformations, we wished to investigate the effect of the methoxy substituent at the C3 position on the "upper" aryl group (see Figure 1 for numbering). It has been hypothesized that the methoxy substituent enhances the rate of reductive elimination. ${ }^{1 \mathrm{f}}$ To test this hypothesis, we prepared a hybrid ligand L3 with a "lower" aryl ring identical to $\mathbf{L 1}$ and an "upper" aryl ring identical to L6. $^{29}$ As in a previous publication describing an L6 based Pd(II) complex, ${ }^{15 a}$ the ${ }^{1} \mathrm{H}$ and ${ }^{31} \mathrm{P}$ NMR of $\mathbf{A} 3$ is consistent with a $C$-bound $\mathrm{Pd}(\mathrm{II})$ isomer A3-C interconverting with an O-bound $\mathrm{Pd}(\mathrm{II})$ isomer A3-O (Chart 4, scheme inset). The ${ }^{31} \mathrm{P}$ NMR resonance for the isomer A3-C is at $45.4 \mathrm{ppm}$ while the resonance for the isomer A3-O is observed at 44.3 ppm (relative to $85 \mathrm{wt} \% \mathrm{H}_{3} \mathrm{PO}_{4}$ at room temperature). 
Chart 3. Rate of Reductive Elimination for Palladium Amido Complexes As Measured by ${ }^{31} \mathrm{P}$ NMR

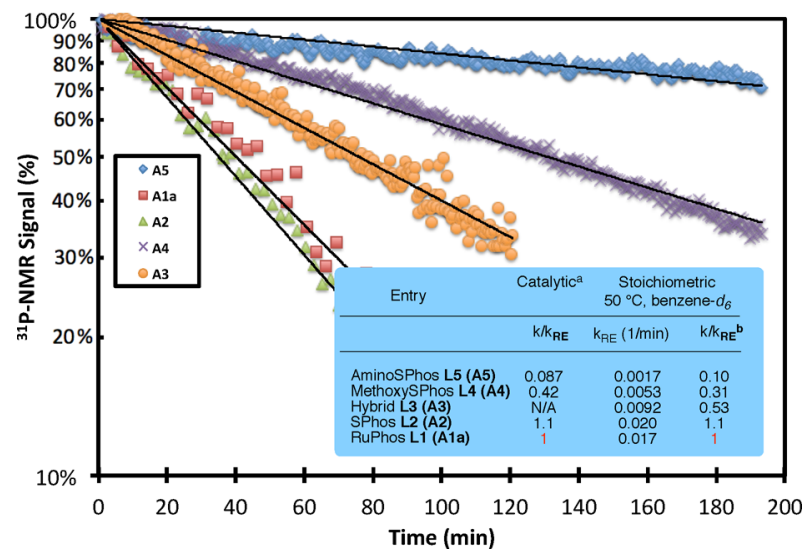

${ }^{a}$ Catalytic rate data from Table $3 .{ }^{b}$ Rate relative to the rate of reductive elimination of Ala.

Chart 4. Rate of Reductive Elimination of the L3 Based Amido Complex (A3) As Measured by ${ }^{31} \mathrm{P}$ NMR

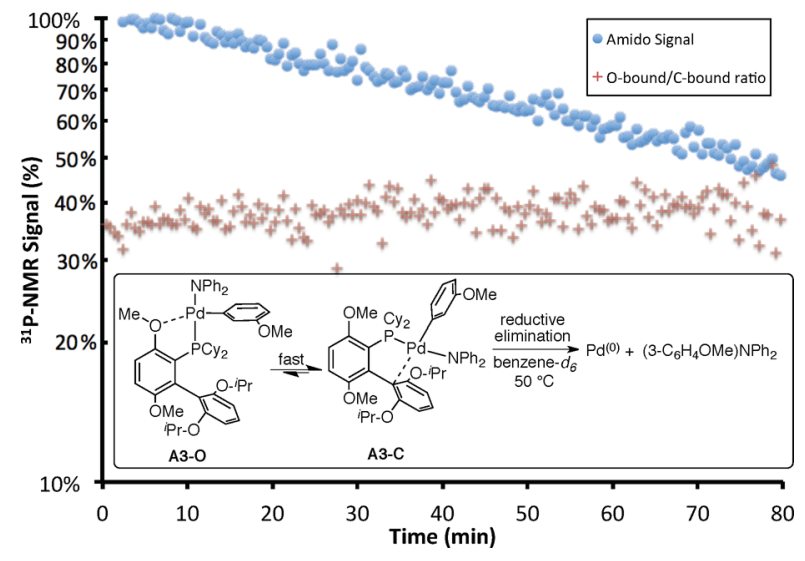

Monitoring these two resonances by ${ }^{31} \mathrm{P}$ NMR at $50{ }^{\circ} \mathrm{C}$, we determined that the average rate of reductive elimination for $\mathbf{A} 3$ was half that of the $\mathbf{L} \mathbf{1}$ based amido complex A1a. It is important to note that the ratio of the ${ }^{31} \mathrm{P}$ NMR signals assigned to the two isomeric amido complexes (A3-O and A3C; see Chart 4) remained constant throughout the course of the reaction, which indicates that the rate of isomerization ${ }^{30}$ is faster than the rate of reductive elimination.

Since the $\mathbf{L} \mathbf{3}$ possesses a "lower" ring that is identical to the one in L1, we would expect that the rate of reductive elimination from corresponding $C$-bound amido complex is quite similar. Since the rate of reductive elimination from an $\mathbf{L} 3$ based amido complex (A3) is less than the rate reductive elimination from an $\mathbf{L 1}$ based amido complex (A1a), this suggests that reductive elimination from the $O$-bound isomer is either much slower or does not occur to an appreciable extent. This suggests that the methoxy substituent at the $\mathrm{C} 3$ position (see Figure 1 for numbering) in this case retards the overall rate of reductive elimination. ${ }^{31}$

To further support this argument and because of the structural similarity of $\mathbf{L} \mathbf{1}$ and L3, we obtained an X-ray crystal structure of A3 (Figure 2) for comparison to A1a (Figure 1). In comparing the two complexes, we found no significant structural differences, which suggests that presence of the methoxy substituent has little role in altering the steric or

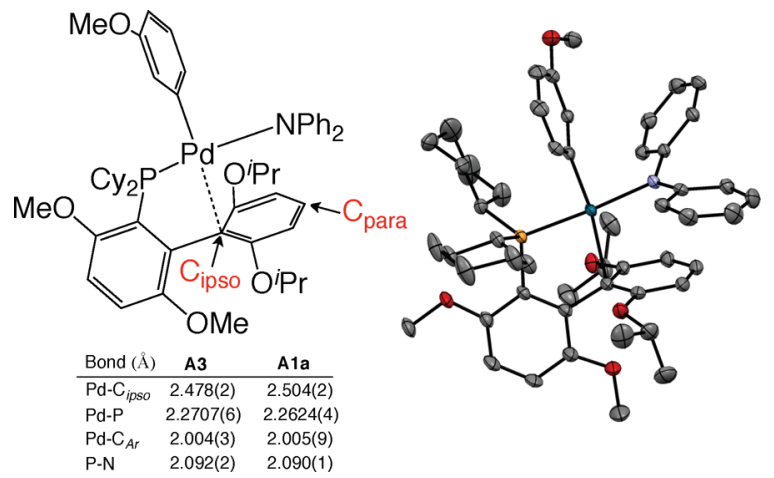

Figure 2. ORTEP drawing of $(\mathbf{L 3}) \mathrm{Pd}\left(\mathrm{NPh}_{2}\right)\left(3-\mathrm{C}_{6} \mathrm{H}_{4} \mathrm{OMe}\right), \mathbf{A}$. Hydrogen atoms have been omitted for clarity.

electronic properties of the C-bound isomer (A3-C). In summary, both the kinetic and structural evidence comparing the $\mathbf{L} 1$ and $\mathbf{L} 3$ based amido complexes (A1a and A3) suggests that the methoxy substituent found in an L6 based amido complex slows the rate of reductive elimination when compared to the $\mathbf{L} 7$ based amido complex.

\section{CONCLUSION}

In summary, kinetics for the reductive elimination of IV were investigated by reaction calorimetry. When RuPhos (L1) was employed as the supporting ligand, the palladium(II) amido complex was identified as the resting state for the crosscoupling of diarylamines with aryl halides. Moreover, relative rates measured under catalytic and stoichiometric conditions were generally found to be in good agreement (Chart 2).

By measuring the rate of a model reaction, we were able to calculate a lower limit (via eq 2) for the reductive elimination rate constant in cases where the corresponding amido complexes could not be isolated (Table 3). These studies also indicated that the electronic properties of the "lower" aryl ring were key to stabilizing these complexes from reductive elimination. This finding was confirmed by isolating and characterizing the corresponding stable amido complexes (Table 4; Chart 3). Surprisingly, the presence of a methoxy substituent at the $\mathrm{C} 3$ position (Figure 1 ; Chart 4) allowed the formation of an O-bound palladium isomer (A3-O), which retarded the overall rate of reductive elimination.

In the context of previously reported palladium(II) amido complexes, the $\mathbf{L} \mathbf{1}$ based palladium(II) amido complexes investigated in this study underwent reductive elimination at rates in between those previously observed for T-shaped palladium(II) amido complexes and DPPF based palladium(II) amido complexes. ${ }^{13 e, 25}$ Consistent with computational studies, ${ }^{32}$ complexes that were stable at room temperature required an electron-rich "lower" aryl ring to maximize coordination with the palladium and an electron-deficient secondary amine. On the basis of work by Hartwig and co-workers, palladium(II) amido complexes based on L1 with more nucleophilic amines, such as anilines, primary alkyl amines, alkyl $N$-substituted aniline, or secondary aliphatic amines, would undoubtedly undergo reductive elimination at room temperature. ${ }^{13,25}$ Notably, this study implies that reductive elimination is not a kinetically difficult step for a significant number of palladiumcatalyzed $\mathrm{C}-\mathrm{N}$ cross-coupling reactions employing biarylphosphine ligands. Future work will investigate the kinetics of other palladium-catalyzed amination reactions and the implications 
for the development of room temperature $\mathrm{C}-\mathrm{N}$ cross-coupling reactions.

\section{ASSOCIATED CONTENT}

\section{S Supporting Information}

The Supporting Information is available free of charge on the ACS Publications website at DOI: 10.1021/jacs.6b05990.

Crystallographic information for Ala (CIF)

Crystallographic information for A3 (CIF)

Experimental procedures, characterization, kinetic data, gas chromatograph measurements, NMR data, and mathematical derivation of proposed mechanism (PDF)

\section{AUTHOR INFORMATION}

\section{Corresponding Authors}

*pedro.arrechea@gmail.com

*sbuchwal@mit.edu

\section{Notes}

The authors declare the following competing financial interest(s): MIT has patents on ligands used during the course of this research, from which S.L.B. and coworkers receive royalty payments.

\section{ACKNOWLEDGMENTS}

The research reported in this publication was supported by the National Institutes of Health under Award GM058160. We would like to thank the National Institutes of Health for a supplement under Award 3-R01-GM058160-14S1. We thank Dr. Peter Müller (Massachusetts Institute of Technology, MIT) for X-ray structural analysis. We thank Dr. Yiming Wang (MIT) and Dr. Michael Pirnot (MIT) for assistance in preparation of the manuscript. We would like to kindly thank the reviewers for detailed suggestions and corrections of the manuscript.

\section{REFERENCES}

(1) (a) Schlummer, B.; Scholz, U. Adv. Synth. Catal. 2004, 346, 1599. (b) Surry, D. S.; Buchwald, S. L. Angew. Chem., Int. Ed. 2008, 47, 6338. (c) Wolfe, J. P.; Wagaw, S.; Marcoux, J.-F.; Buchwald, S. L. Acc. Chem. Res. 1998, 31, 805. (d) Affouard, C.; Crockett, R. D.; Diker, K.; Farrell, R. P.; Gorins, G.; Huckins, J. R.; Caille, S. Org. Process Res. Dev. 2015, 19, 476. (e) Buchwald, S. L.; Mauger, C.; Mignani, G.; Scholz, U. Adv. Synth. Catal. 2006, 348, 23. (f) Surry, D. S.; Buchwald, S. L. Chem. Sci. 2011, 2, 27. (g) Federsel, H.-J.; Hedberg, M.; Qvarnström, F. R.; Tian, W. Org. Process Res. Dev. 2008, 12, 512.

(2) (a) Cooper, T. W. J.; Campbell, I. B.; Macdonald, S. J. F. Angew. Chem., Int. Ed. 2010, 49, 8082. (b) Roughley, S. D.; Jordan, A. M. J. Med. Chem. 2011, 54, 3451. (c) Walters, W. P.; Green, J.; Weiss, J. R.; Murcko, M. A. J. Med. Chem. 2011, 54, 6405.

(3) (a) Louie, J.; Hartwig, J. F. Tetrahedron Lett. 1995, 36, 3609.

(b) Louie, J.; Paul, F.; Hartwig, J. F. Organometallics 1996, 15, 2794.

(c) Guram, A. S.; Buchwald, S. L. J. Am. Chem. Soc. 1994, 116, 7901.

(d) Paul, F.; Patt, J.; Hartwig, J. F. J. Am. Chem. Soc. 1994, 116, 5969.

(e) Hartwig, J. F.; Paul, F. J. Am. Chem. Soc. 1995, 117, 5373.

(4) $\mathrm{DPPF}=1,1^{\prime}$-bis (diphenylphosphino)ferrocene. BINAP $=2,2^{\prime}$ bis(diphenylphosphine)-1,1'-binaphthalene.

(5) (a) Wolfe, J. P.; Wagaw, S.; Buchwald, S. L. J. Am. Chem. Soc. 1996, 118, 7215. (b) Louie, J.; Driver, M. S.; Hamann, B. C.; Hartwig, J. F. J. Org. Chem. 1997, 62, 1268. (c) Wolfe, J. P.; Buchwald, S. L. Angew. Chem., Int. Ed. 1999, 38, 2413.

(6) (a) Yamamoto, T.; Nishiyama, M.; Koie, Y. Tetrahedron Lett. 1998, 39, 2367. (b) Nishiyama, M.; Yamamoto, T.; Koie, Y. Tetrahedron Lett. 1998, 39, 617. (c) Hartwig, J. F.; Kawatsura, M.;
Hauck, S. I.; Shaughnessy, K. H.; Alcazar-Roman, L. M. J. Org. Chem. 1999, 64, 5575 .

(7) (a) Old, D. W.; Wolfe, J. P.; Buchwald, S. L. J. Am. Chem. Soc. 1998, 120, 9722. (b) Anderson, K. W.; Tundel, R. E.; Ikawa, T.; Altman, R. A.; Buchwald, S. L. Angew. Chem., Int. Ed. 2006, 45, 6523. (c) Wolfe, J. P.; Tomori, H.; Sadighi, J. P.; Yin, J.; Buchwald, S. L. J. Org. Chem. 2000, 65, 1158.

(8) (a) Hamann, B. C.; Hartwig, J. F. J. Am. Chem. Soc. 1998, 120, 7369. (b) Hartwig, J. F. Acc. Chem. Res. 2008, 41, 1534. (c) Kataoka, N.; Shelby, Q.; Stambuli, J. P.; Hartwig, J. F. J. Org. Chem. 2002, 67, 5553.

(9) (a) Wolfe, J. P.; Buchwald, S. L. Tetrahedron Lett. 1997, 38, 6359. (b) Marcoux, J.-F.; Wagaw, S.; Buchwald, S. L. J. Org. Chem. 1997, 62, 1568. (c) Ogata, T.; Hartwig, J. F. J. Am. Chem. Soc. 2008, 130, 13848. (d) Stauffer, S. R.; Lee, S.; Stambuli, J. P.; Hauck, S. I.; Hartwig, J. F. Org. Lett. 2000, 2, 1423.

(10) Basolo, F.; Pearson, R. G. Mechanisms of Inorganic Reactions A Study of Metal Complexes in Solutions, 2nd ed.; John Wiley and Sons: New York, 1967.

(11) (a) Widenhoefer, R. A.; Zhong, H. A.; Buchwald, S. L. Organometallics 1996, 15, 2745. (b) Widenhoefer, R. A.; Buchwald, S. L. Organometallics 1996, 15, 3534.

(12) (a) Guram, A. S.; Rennels, R. A.; Buchwald, S. L. Angew. Chem., Int. Ed. Engl. 1995, 34, 1348. (b) Kosugi, M.; Kameyama, M.; Migita, T. Chem. Lett. 1983, 12, 927.

(13) (a) Boncella, J. M.; Villanueva, L. A. J. Organomet. Chem. 1994, 465, 297. (b) Villanueva, L. A.; Abboud, K. A.; Boncella, J. M. Organometallics 1994, 13, 3921. (c) Stambuli, J. P.; Incarvito, C. D.; Bühl, M.; Hartwig, J. F. J. Am. Chem. Soc. 2004, 126, 1184. (d) Klinkenberg, J. L.; Hartwig, J. F. J. Am. Chem. Soc. 2010, 132, 11830. (e) Yamashita, M.; Hartwig, J. F. J. Am. Chem. Soc. 2004, 126, 5344. (f) Driver, M. S.; Hartwig, J. F. J. Am. Chem. Soc. 1995, 117, 4708. (g) Driver, M. S.; Hartwig, J. F. J. Am. Chem. Soc. 1997, 119, 8232. (h) Driver, M. S.; Hartwig, J. F. J. Am. Chem. Soc. 1996, 118 7217.

(14) (a) Hoffmann, R. Reductive Elimination. In IUPAC. Frontiers of Chemistry; Laidler, K. J., Ed.; Pergamon Press: Oxford, 1982; pp 247263. (b) Tatsumi, K.; Hoffmann, R.; Yamamoto, A.; Stille, J. K. Bull. Chem. Soc. Jpn. 1981, 54, 1857.

(15) (a) Fors, B. P.; Watson, D. A.; Biscoe, M. R.; Buchwald, S. L. J. Am. Chem. Soc. 2008, 130, 13552. (b) Milner, P. J.; Maimone, T. J.; Su, M.; Chen, J.; Müller, P.; Buchwald, S. L. J. Am. Chem. Soc. 2012, 134, 19922.

(16) (a) Biscoe, M. R.; Barder, T. E.; Buchwald, S. L. Angew. Chem., Int. Ed. 2007, 46, 7232. (b) Biscoe, M. R; Fors, B. P.; Buchwald, S. L. J. Am. Chem. Soc. 2008, 130, 6686.

(17) Lee, H. G.; Milner, P. J.; Buchwald, S. L. J. Am. Chem. Soc. 2014, 136, 3792.

(18) Milne, J. E.; Buchwald, S. L. J. Am. Chem. Soc. 2004, 126, 13028.

(19) These reactions are often carried with an excess of phosphine ligand relative to the palladium metal for a range of palladium sources (e.g., $\left.\mathrm{Pd}_{2} \mathrm{dba}_{3}, \operatorname{Pd}(\mathrm{OAc})_{2}\right)$. See for example: (a) Surry, D. S.; Buchwald, S. J. Am. Chem. Soc. 2007, 129, 10354. (b) Fors, B. P.; Krattiger, P.; Strieter, E.; Buchwald, S. L. Org. Lett. 2008, 10, 3505. (c) Ruiz-Castillo, P.; Blackmond, D. G.; Buchwald, S. L. J. Am. Chem. Soc. 2015, 137, 3085. (d) Bruno, N. C.; Tudge, M. T.; Buchwald, S. L. Chem. Sci. 2013, 4, 916.

(20) See Supporting Information for derivation of this equation.

(21) For reaction temperatures of 110,100 , and $90{ }^{\circ} \mathrm{C}$ gas chromatography experiments were used to quantify the rate of reaction. The differential form of eq 1 was used (see Supporting Information): $k_{\mathrm{RE}}=\frac{1}{\left(\mathrm{Pd}_{\mathrm{ratio}}\right)} \frac{\mathrm{d} c}{\mathrm{~d} t}$ where $c$ is the conversion of the limiting reagent and takes a (dimensionless) value between 0 and 1 . For a temperature of $78{ }^{\circ} \mathrm{C}$, the reaction was not homogeneous, and thus calorimetry (which employs stirring) was used.

(22) The values determined in this study are comparable to those found for platinum based reductive eliminations. The $\Delta H^{\ddagger}$ and $\Delta S^{\ddagger}$ values for the reductive elimination of biaryl from $\mathrm{Pt}\left(\mathrm{PPh}_{3}\right)_{2}\left(\mathrm{C}_{6} \mathrm{H}_{4}\right.$ - 
$\left.p \mathrm{CH}_{3}\right)_{2}$ have been reported to be $17.6 \mathrm{kcal} / \mathrm{mol}$ and $-23 \mathrm{cal} /(\mathrm{mol} \mathrm{K})$. For the reductive elimination of ethane from $\mathrm{Pt}\left(\mathrm{Me}_{3} \mathrm{I}\left(\mathrm{PMePh}_{2}\right)_{2}\right)$, the reported values are $31 \mathrm{kcal} / \mathrm{mol}$ and $21 \mathrm{cal} /(\mathrm{mol} \mathrm{K})$. For the reductive elimination of 1,1,1-trifluoroethane from cis- $\mathrm{PtH}\left(\mathrm{CH}_{2} \mathrm{CF}_{3}\right)\left(\mathrm{PPh}_{3}\right)_{2}$, the reported values range from 25.4 to $23.9 \mathrm{kcal} / \mathrm{mol}$ and 7.8 to $2 \mathrm{cal} /$ $(\mathrm{mol} \mathrm{K})$ and are dependent upon the reaction solvent. For references, see: (a) Brown, M. P.; Puddephatt, R. J.; Upton, C. E. E. J. Organomet. Chem. 1973, 49, C61. (b) Braterman, P. S.; Cross, R. J.; Young, G. B. J. Chem. Soc., Dalton Trans. 1977, 1892. (c) Michelin, R. A.; Faglia, S.; Uguagliati, P. Inorg. Chem. 1983, 22, 1831.

(23) We attribute the difference to three factors: (1) The calculation of the rate constant under catalytic conditions inherently overestimates the stability of the amido complex IV since it does not consider other elementary steps such as oxidative addition, possible off-cycle palladium species, or low level impurities that may deactivate a portion of the catalyst. (2) The extrapolation to $40{ }^{\circ} \mathrm{C}$ is well outside the studied temperature range $78-110{ }^{\circ} \mathrm{C}$, and (3) the effect of changing the solvent from 1,4-dioxane to benzene- $d_{6}$ (and solvated base, amine, and aryl halide) of the reaction has an unknown role on the rate of the reductive elimination.

(24) Catalyst decomposition over the course of the reaction is also an alternative possibility and cannot be ruled out as the cause of decreasing reaction rate.

(25) (a) Mann, G.; Baranano, D.; Hartwig, J. F.; Rheingold, A. L.; Guzei, I. A. J. Am. Chem. Soc. 1998, 120, 9205. (b) Hartwig, J. F. Inorg. Chem. 2007, 46, 1936.

(26) Reid, S. M.; Boyle, R. C.; Mague, J. T.; Fink, M. J. J. Am. Chem. Soc. 2003, 125, 7816.

(27) It was determined that additional $\mathbf{L 8}$ improved the rate of reaction. This is most consistent with the formation of an off-cycle palladium species for which reassociation with the ligand forms the active catalyst. This does not affect our ability to calculate a lower limit of the rate constant for reductive elimination.

(28) (a) Cho, E. J.; Senecal, T. D.; Kinzel, T.; Zhang, Y.; Watson, D. A.; Buchwald, S. L. Science 2010, 328, 1679. (b) Ball, N. D.; Gary, J. B.; Ye, Y.; Sanford, M. S. J. Am. Chem. Soc. 2011, 133, 7577. (c) Park, N. H.; Vinogradova, E. V.; Surry, D. S.; Buchwald, S. L. Angew. Chem., Int. Ed. 2015, 54, 8259. (d) Hicks, J. D.; Hyde, A. M.; Cuezva, A. M.; Buchwald, S. L. J. Am. Chem. Soc. 2009, 131, 16720.

(29) We were unable to isolate examples of $\operatorname{LPd}(\mathrm{Ar})\left(\mathrm{NAr}_{2}{ }_{2}\right)$ for $\mathbf{L 6}$ or $\mathbf{L} 7$ as they both readily undergo reductive elimination at room temperature.

(30) Cross, R. J. Chem. Soc. Rev. 1985, 14, 197.

(31) The role of different phosphine substituents (e.g., tbutyl vs cyclohexyl), which likely affects the $O$-bound and $C$-bound equilibrium, has an unknown effect on the rate of reductive elimination. The coordination to the 3-methoxy substituent may be lessened, and reductive elimination may be favored by the combination of the steric pressure due to the tbutyl groups in conjunction with the methoxy substituent.

(32) Barder, T. E.; Buchwald, S. L. J. Am. Chem. Soc. 2007, 129, 12003.

\section{NOTE ADDED AFTER ASAP PUBLICATION}

This paper was published ASAP on September 13, 2016, with a graphic missing from Figure 1. The corrected version was reposted on September 15, 2016. 